\title{
POR LA TRANSMISIBILIDAD DE LA ACCIÓN A FAVOR DE LOS HEREDEROS PARA RECLAMAR EL DAÑO MORAL DE SU CAUSANTE
}

\author{
FOR THE TRANSMISSIBILITY OF THE ACTION IN FAVOR \\ OF THE HEIRS TO CLAIM THE MORAL DAMAGES OF ITS \\ ORIGINATOR
}

\author{
DENNISSE DÍAZ DUARTE* \\ Universidad Diego Portales \\ Santiago, Chile
}

\section{RESUMEN}

En este trabajo se pretende defender la posibilidad de la transmisibilidad de la acción indemnizatoria por daño moral en el ordenamiento jurídico chileno. Para lo anterior se hará una breve reseña sobre el problema jurídico planteado junto con atender a la noción de daño moral y su finalidad en la indemnización; además se analizarán las características de los derechos personalísimos en relación con el daño moral y su acción para reclamarlo; y por último, se explicará la existencia de un proceso de transición desde lo extrapatrimonial a lo patrimonial a través de la avaluación pecuniaria de la indemnización del daño moral.

Palabras clave: Acción, daño moral, derechos personalísimos, transmisibilidad de la acción.

\footnotetext{
* Egresada de Derecho y candidata a Magíster en Derecho Civil Patrimonial por la Universidad Diego Portales. Avenida República 112, Santiago. Correo electrónico: dennisse.diaz@mail.udp.cl. Artículo recibido el 24 de mayo de 2017 y aceptado para su publicación el 10 de junio de 2017.
} 


\section{ABSTRACT}

This paper aims to defend the possibility of the transmissibility of compensatory action for moral damages in the Chilean legal system. For the aforementioned, a brief review will be made of the juridical problem raised together with attention to the notion of moral damages and its purpose in compensation; in addition, it will be analyzed the characteristics of personal rights in relation to moral damages and their action to claim it; finally, we will explain the existence of a process of transition from the extrapatrimonial to the patrimonial through the pecuniary assessment of compensation for moral damages.

Keywords: Action (compensatory action), moral damages, personal rights, transmissibility of action.

\section{INTRODUCCIÓN}

Un aspecto que ha suscitado controversia en la doctrina, tanto nacional como comparada, dice relación con los herederos que actúan iure hereditatis, es decir, aquellas que intervienen en el juicio de indemnización de perjuicios como continuadoras de la persona del causante, de acuerdo a lo establecido en los artículos 951 y 1097 del Código Civil.

Lo que se cuestiona sobre este punto es si puede transmitirse la acción indemnizatoria por daño moral a los herederos de la víctima directa cuando éste fallece producto del acaecimiento de un hecho dañoso. Este planteamiento se circunscribe solamente al daño moral, puesto que no existe controversia sobre la transmisibilidad de la acción para reclamar la indemnización de los daños patrimoniales.

De acuerdo con lo anterior, la doctrina nacional se encuentra dividida. A este respecto, algunos están por rechazar la tesis de la transmisibilidad de la acción, ${ }^{1}$ mientras que otros están por acogerla. ${ }^{2}$ En cuanto a la jurisprudencia

\footnotetext{
1 En este sentido: AlessANDRI RodRíguez, Arturo, De la responsabilidad extracontractual en el derecho civil chileno. Editorial Jurídica, Santiago, 2005 (reimpresión), pp. 468-469; Domínguez Hidalgo, Carmen, El daño moral, Editorial Jurídica, Santiago, 2000, pp. 729-736; DomínguEz ÁGuILA, Ramón, "Sobre la transmisibilidad de la acción por daño moral", Revista Chilena de Derecho, 2004, vol. 31 N $^{\circ}$ 3; Barros Bourie, Enrique, Tratado de responsabilidad extracontractual, Editorial Jurídica, Santiago, 2006, pp. 943-947; CORRAL TALCIANI, Hernán, Lecciones sobre la responsabilidad extracontractual, Thomson Reuters, Santiago, 2013, pp. 356-359.

2 En este sentido: Bidart Hernández, José, Sujetos de la acción de responsabilidad extracontractual, Editorial Jurídica, Santiago, 1985, pp. 80-93; RodríGUEz GrEz, Pablo, Responsabilidad extracontractual,
} 
nacional, la tendencia en las Cortes de Apelaciones ha sido el rechazo de la transmisibilidad de la acción, ${ }^{3}$ decisiones que han sido mantenidas por la Corte Suprema, siendo el argumento principal aquel que dice relación con el carácter personalísimo de la indemnización por daño moral, unido a la naturaleza del daño función en la indemnización.

No obstante lo anterior, en un actual fallo dictado por el máximo tribunal de justicia, se acoge un recurso de unificación de jurisprudencia en el que se postula la transmisibilidad de la acción por daño moral, aunque limitado en concreto al ámbito de accidentes laborales. ${ }^{4}$

Cabe señalar que este problema de la transmisibilidad de acción indemnizatoria suele darse en sede laboral, en específico en cuanto a accidentes del trabajo. A este respecto, frente a un accidente laboral surgen dos escenarios: el primero se refiere a aquel en que acciona el trabajador afectado en contra del empleador o sus herederos en calidad de continuadores de su persona, siendo una responsabilidad de naturaleza contractual; el segundo escenario es aquel en que accionan en contra del empleador las víctimas por repercusión o rebote, donde la responsabilidad es extracontractual. ${ }^{5}$

En síntesis, frente al problema de la transmisibilidad de acción por daño moral cabría señalar un criterio dispar en opinión de la doctrina y en el caso de la jurisprudencia existe una tendencia a su rechazado.

Para abordar la problemática planteada en este trabajo, nos referiremos de manera breve a la noción de daño moral y la finalidad de su indemnización. Luego, analizaremos los aspectos relevantes de los derechos personalísimos y se relacionarán con la acción indemnizatoria; finalmente, aludiremos a la patrimonialidad de la acción indemnizatoria, para concluir en la transmisibilidad de la acción.

Editorial Jurídica, Santiago, 2002, pp. 360-368.

3 Corte de Apelaciones de Concepción, 26 de abril de 2003, Rol N 4825-2003; Corte de Apelaciones de Concepción, 12 de diciembre de 2007, Rol N 423-2007; Corte de Apelaciones de Valdivia, 20 de abril de 2010, Rol No 52-2010; Corte de Apelaciones de Santiago, 8 de noviembre de 2011, Rol No 1910-2011; Corte de Apelaciones de San Miguel, 4 de mayo de 2016, Rol No 84-2016; Corte Suprema, 27 de diciembre de 2016, Rol No 33.990-2016.

4 Corte Suprema, 27 de diciembre de 2016, María Quezada Gallardo con Colmenares Werner Limitada, Rol N³3.990-2016.

5 Diez Schwerter, José L., "La culpa del empresario por accidentes del trabajo: Modernas tendencias jurisprudenciales", en Baraona González, J.; Zelaya Etchegaray, P. (Coords.), La responsabilidad por accidentes del trabajo. Cuadernos de Extensión Jurídica $\mathrm{N}^{\mathrm{o}}$ 10, Universidad de los Andes, Santiago, 2005, p. 94. 


\section{NOCIÓN DE DAÑO MORAL Y FINALIDAD DE SU INDEMNIZACIÓN}

La noción de daño moral y su finalidad en la indemnización de perjuicios repercutirá de manera directa en la calificación acerca de si la acción impetrada por los herederos como continuadores de la persona del causante resulta transmisible.

En cuanto al reconocimiento del daño moral en la responsabilidad civil, este se identificó en un primer momento con las aflicciones físicas y psicológicas que experimentaban los individuos frente a la producción de un ilícito, es lo que se denominó como pretium doloris. De esta manera, Alessandri lo definió como "el dolor, pesar o molestia que sufre una persona en su sensibilidad física o en sus sentimientos, creencias o afectos". ${ }^{6}$

En la actualidad existe unanimidad en cuanto a señalar que la concepción tradicional de daño moral resulta restringida y no abarca todos los casos en que puede producirse un perjuicio de este tipo. En consecuencia, un correcto entendimiento nos lleva a calificar al pretium doloris como una de las tantas manifestaciones de daño moral.

Al respecto, la Corte Suprema ha señalado que "esta visión ha dado paso, tanto en la doctrina como en la jurisprudencia, a considerar una concepción más amplia de tal concepto a fin de reparar todas las especies de perjuicios morales y no sólo el pretium doloris toda vez que en cada una de ellas hay atentados a intereses extrapatrimoniales diversos". ${ }^{7}$

En virtud de lo anterior, cabe concluir que en la actualidad se ha adoptado una noción amplia de daño moral ya no limitada solamente al pretium doloris, es por ello que en este trabajo debemos introducir una categoría a indemnizar como rubro de daño moral cual es la fractura al plan o proyecto de vida, categoría introducida en el derecho comparado por Fernández Sessarego en Perú, quien manifiesta que se trata de una potencialidad que le permite a las personas elegir entre muchas posibilidades de vida, ${ }^{8}$ y por Burgos en Argentina, quien alude que las personas tienen un proyecto de vida y que si este se ve interrumpido por un hecho dañoso, merece resarcimiento. ${ }^{9}$

En consecuencia, lo que postulamos es que lo que se indemniza en caso

6 Alessandri Rodríguez, cit. (n. 1), pp. 160-161.

7 Corte Suprema, 29 de septiembre de 2011, Ricardo Armando Mellao Calfuan y María Francisca Llancao Colin con Fisco de Chile, Rol No 2073-2009.

8 Fernández Sessarego, Carlos, "El daño al proyecto de vida", Revista de Derecho de la Pontificia Universidad Católica del Perú, 1996, N 50.

9 Burgos, Osvaldo, Daños al proyecto de vida, Astrea, Buenos Aires, 2012, 440 pp. 
de fallecimiento de la víctima es la fractura al plan de vida, siendo esta una de las manifestaciones del daño moral y correspondiendo a este tipo de perjuicio queda referirnos a la finalidad que cumple su indemnización.

Se ha señalado por la doctrina nacional que la indemnización de perjuicios cumple una triple función, cuales son la punitiva, preventiva y reparatoria, primando esta última por sobre las demás.

En los casos de daños patrimoniales la naturaleza jurídica de la indemnización corresponde al equivalente monetario del bien afectado, calificándose tal circunstancia como una finalidad reparatoria; en caso de los daños extrapatrimoniales dicha función no puede tener cabida sino como una compensación o una satisfacción alternativa, porque en estos supuestos los bienes jurídicos afectados no son susceptibles de apreciación pecuniaria.

De acuerdo a lo expresado con anterioridad, Barrientos Zamorano alude que "la reparación por el dinero entonces sólo cumple un rol como medida común de los bienes, pero no reemplaza la aflicción. Sustituye en el caso de los bienes materiales la obligación incumplida por medio de la indemnización, pero en los daños extrapatrimoniales esto no puede realizarse". ${ }^{10}$ Por su parte, Barros ha señalado que "los daños morales son perjuicios inconmensurables en dinero, porque no existe mercado para la vida, la salud o el honor". ${ }^{11}$

En síntesis, en el caso de la indemnización del daño moral la finalidad que cumple es una de tipo compensatoria o una satisfacción alternativa, en la cual mediante la entrega de una suma de dinero se pretende dar a la víctima otras formas de reparaciones que intenten aplacar el perjuicio causado.

\section{MÁS ALLÁ DE LO PERSONALÍSIMO EN EL DAÑO MORAL}

Existe consenso tanto en la doctrina como en la jurisprudencia en señalar que el daño moral es personalísimo, y es en virtud de esa aseveración que niegan que la acción para reclamar su indemnización sea transmisible. En atención a lo anterior, es que nos referiremos a los distintos criterios que han calificado a una situación jurídica como personalísima, para concluir que la acción indemnizatoria no responde a dichas características.

La doctrina francesa se ha referido a los derechos personalísimos como una manifestación de los derechos personales, así se le ha otorgado tres

\footnotetext{
${ }^{10}$ Barrientos Zamorano, Marcelo, "Del daño moral al daño extrapatrimonial: la superación del pretium doloris”, Revista Chilena de Derecho, 2008, vol. 35 N 1, p. 96.

${ }^{11}$ Barros Bourie, cit. (n. 1), p. 288.
} 
sentidos: el primero alude a los derechos intransmisibles, el segundo a aquellos derechos inembargables y, por último, aquellos derechos personales unidos completamente a la persona de su titular. ${ }^{12}$

En el ámbito nacional, siguiendo la tradición francesa, se ha señalado que lo personalísimo se entiende en dos sentidos, para atender a los derechos intransmisibles y cuando su ejercicio es exclusivamente personal. ${ }^{13}$

En virtud de lo anterior, cabe concluir que el carácter personalísimo de un derecho está constituido, esencialmente, por su inherencia o inseparabilidad con la persona de su titular, resultando, por lo tanto, intransferibles e intransmisibles.

Nos referiremos a continuación a los criterios que hemos considerado para calificar a un derecho como personalísimo, así entonces encontramos de tres tipos, uno económico, uno de orden público y uno referido a la confianza.

\section{Criterio económico}

En relación con este criterio encontramos el Fideicomiso, el Derecho de Usufructo y el Derecho de Uso y Habitación. Estos derechos corresponden a derechos reales limitados, los cuales importan un desmembramiento o fracción del dominio o la propiedad. ${ }^{14}$

Al respecto, se ha manifestado que el derecho de propiedad es uno de los derechos más completos, esto porque posee tres atributos, que de acuerdo con los romanos sería el jus utendi relativo al derecho a usar la cosa, el jus fruendi que sería el derecho de gozar la cosa o percibir sus frutos; y el jus abutendi que se traduce en el derecho de disposición. ${ }^{15}$ Además, los derechos de usufructo y los de uso y habitación encuentran estas facultades disociadas en varios titulares, por lo que la propiedad se encuentra desmembrada, así por ejemplo, el usufructo tiene el usus y fructus, mientras que el abusus lo detenta el nudo propietario. ${ }^{16}$

\footnotetext{
12 Planiol, Marcel; Ripert, Georges, Tratado elemental de Derecho Civil. José M. Cajica (trad.), Cardenas Editor y Distribuidor, México D.F., 1983, pp. 19-20.

${ }^{13}$ En este sentido: Claro Solar, Luis, Explicaciones de derecho civil chileno y comparado, Editorial Jurídica, Santiago, 1992, Vol. III, p. 21; AlESSANDri Rodríguez, Arturo, Derecho Civil: título preliminar. De las personas, Editorial Lex, Santiago, 1933, pp. 180-181.

${ }^{14}$ En este sentido: Alessandri Rodríguez, Arturo; Somarriva Undurraga, Manuel; Vodanovic Haklicka, Antonio, Tratado de los derechos reales, Ediciones Jurídicas de Santiago, Santiago, 2016, p. 83; Peñailillo Arévalo, Daniel, Los bienes, Editorial Jurídica, Santiago, 2006, pp. 437.

${ }^{15}$ Mazeaud, Henri; Mazeaud, León; Mazeaud, Jean, Lecciones de Derecho Civil. Luis Alcalá-Zamora y Castillo (trad.), Ediciones jurídicas Europa-América, Buenos Aires, 1959, p. 260.

${ }^{16}$ Ídem.
} 
Sobre este mismo punto, Claro Solar alude que "la propiedad expresa la idea del poder jurídico más completo de la persona sobre una cosa; y es, por lo tanto, el derecho real en virtud del cual una cosa se halla sometida, de una manera absoluta y exclusiva, a la voluntad y a la acción de una persona". ${ }^{17}$

En síntesis, el fundamento que está detrás del criterio económico para catalogar a un derecho como intransmisible dice relación precisamente con que estos derechos importan un fraccionamiento del derecho de propiedad con sus facultades, cuales son el uso, goce y disposición; en consecuencia, la facultad de disposición sólo tiene cabida cuando se trata de la propiedad plena o completa. Esto quiere decir que la regla de la transmisión en este tipo de derechos sólo tiene lugar cuando confluyen las tres facultades del dominio, siendo una excepción a lo anterior la intransmisibilidad cuando aquéllas se encuentran limitadas.

En el caso del fideicomiso, de acuerdo con el artículo 762 del Código Civil que señala: "El fideicomisario que fallece antes de la restitución, no transmite por testamento o abintestato derecho alguno sobre el fideicomiso, ni aun la simple expectativa, que pasa ipso jure al substituto o substitutos designados por el constituyente, si los hubiere"; podemos entender que el derecho del fideicomisario respecto del fideicomiso es personalísimo.

En el usufructo, su carácter personalísimo lo podemos encontrar en el artículo 765 inciso 2 del Código Civil, el que estipula que "tiene por consiguiente una duración limitada, al cabo de la cual pasa al nudo propietario, y se consolida con la propiedad." A este respecto, cabe señalar que este derecho se puede ceder mientras viva el titular, pero se extingue con su muerte, lo que denota un carácter intransmisible.

En el derecho de uso y habitación, por su parte, queda de manifiesto su carácter personalísimo en el artículo 819 del Código Civil, el cual expresa que "los derechos de uso y habitación son intransmisibles a los herederos, y no pueden cederse a ningún título, prestarse ni arrendarse".

Para justificar la intransmisibilidad de estos derechos hemos postulado que se atiende a un criterio económico, en el cual la regla general de transmisión se prefiere a las facultades plenas del dominio, lo que en estos supuestos no ocurre por tener sus facultades limitadas.

\footnotetext{
${ }^{17}$ Claro Solar, cit. (n. 13), p. 325.
} 


\section{Criterio de orden público}

Dentro de este criterio encontramos el derecho de alimentos y las prestaciones laborales en materia de accidentes laborales.

El fundamento de este criterio se encuentra en que el Estado debe proteger y amparar a determinadas personas que se encuentran en una situación particular, por tratarse de aspectos relevantes de protección en el orden social.

En el caso del derecho de alimentos, la protección mira a favor de aquellas personas en necesidad en la cual se debe garantizar su subsistencia, lo que queda manifestado en el artículo 323 del Código Civil cuando señala que "los alimentos deben habilitar al alimentado para subsistir modestamente de un modo correspondiente a su posición social".

Al respecto Fueyo manifiesta que este derecho tiene un carácter social, donde se concede a aquellas personas que tengan una necesidad actual, existente al momento de la demanda ${ }^{18}$ por su parte, Barcia agrega que tiene una naturaleza protectora y, en consecuencia, que "el Estado tiene un rol asistencial que excede el derecho civil respecto de los grupos más desprotegidos". ${ }^{19}$ Es por lo anterior que se justifica el artículo 334 del Código Civil, el cual estipula que "el derecho de pedir alimentos no puede transmitirse por causa de muerte, ni venderse o cederse de modo alguno, ni renunciarse".

Por su parte, en el caso de las prestaciones otorgadas al trabajador en materias de accidentes laborales podemos encontrarlas en el Título V de la Ley $\mathrm{N}^{\circ} 16.744$ cuales son las prestaciones médicas, prestaciones por incapacidad temporal, prestaciones por invalidez y prestaciones por supervivencia.

Estos derechos responden a un criterio de orden público, razón por la cual se han establecido sólo a favor de aquellos que han sido víctima de un accidente laboral, es por ello que el legislador ha establecido en el artículo 88 de la Ley $\mathrm{N}^{\circ}$ 16.744, que "los derechos concedidos por la presente ley son personalísimos e irrenunciables"; al respecto cabe señalar que este artículo sólo considera las prestaciones laborales en materia de accidentes del trabajo, excluyendo las acciones del artículo 69 del mismo cuerpo legal.

Lo anterior ha sido manifestado por la Corte Suprema, aludiendo que: "En relación a este precepto, debe considerarse que al referirse a los derechos que se confieren al trabajador se alude a aquellos de índole social, en particular

\footnotetext{
${ }^{18}$ Fueyo Laneri, Fernando, Derecho civil: derecho de familia, Ed. Universo, Valparaíso, 1959, p. 554.

${ }^{19}$ Barcia Lehmann, Rodrigo, Fundamentos del derecho de familia y de la infancia, Thomson Reuters, Santiago, 2011, p. 553.
} 
las prestaciones médicas, por incapacidad, invalidez y por supervivencia, contempladas en el Título $V$, pero no alcanza a las acciones indemnizatorias previstas en el artículo 69. Lo contrario significaría que cualquiera sea la naturaleza del daño cuya indemnización se reclama, daño emergente o lucro cesante, no cabría la transmisibilidad, lo que atendido el artículo 2315 del Código Civil resulta impropio". ${ }^{20}$

En razón de lo dicho con anterioridad, el derecho de alimentos y las prestaciones de índole social hacia el trabajador en materia de accidentes laborales, responden a un criterio de orden público, pues se trata de aspectos socialmente relevantes y es el Estado quien tiene que garantizar la observación de dichos derechos, es por ello que miran a la calidad de la persona, siendo calificados, en consecuencia, como derechos personalísimos.

\section{Criterio de confianza}

Dentro de este último criterio encontramos dos instituciones, cuales son el albaceazgo y el contrato de mandato, las que responden a la confianza depositada en la contraparte en la celebración de un negocio jurídico.

La calidad de albacea se encuentra definida en el artículo 1270 del Código Civil como "aquellos a quienes el testador da el encargo de hacer ejecutar sus disposiciones." De acuerdo con Meza Barros, quienes tienen que hacer cumplir las disposiciones de última voluntad son los herederos, pero nada impide que el causante encomiende a una persona la ejecución de sus disposiciones para que se cumplan de un modo seguro, fiel y diligente; ${ }^{21}$ cabe destacar que esa persona elegida por el causante tiene la particularidad que goza de la confianza de aquél, de otra forma no se explicaría la institución.

En este sentido, Elorriaga define a los albaceas como "personas de la confianza del testador a quienes éste les encomienda la ejecución de las disposiciones contenidas en su testamento". ${ }^{22}$

En conclusión, tratándose de un ejecutor testamentario, el criterio de elección de dicha persona se hace en función de la confianza que reporta aquél para el causante, es por esa razón que se trata de una institución personalísima,

\footnotetext{
${ }^{20}$ Corte Suprema, 27 de diciembre de 2016, María Clarisa Quezada Gallardo, Pablo Rafael Miranda Quezada, Marcela Miranda Quezada y Jacqueline Miranda Quezada con Colmenares Werner Limitada, Rol N³3.990-2016.

${ }^{21}$ Meza Barros, Ramón, Manual de la sucesión por causa de muerte y donaciones entre vivos, Editorial Jurídica, Santiago, 2000 (reimpresión), p. 151.

${ }^{22}$ Elorriaga de Bonis, Fabián, Derecho Sucesorio, Legal Publishing, Santiago, 2010, p. 675.
} 
lo que trae como consecuencia que la calidad de albacea será intransferible e intransmisible, cuestión que queda expresamente manifestada en el artículo 1279 del Código Civil que señala al respecto "el albaceazgo no es transmisible a los herederos del albacea".

Por otra parte, el contrato de mandato se define en el artículo 2116 del Código Civil como "un contrato en que una persona confía la gestión de uno o más negocios a otra, que se hace cargo de ellos por cuenta y riesgo de la primera". Siguiendo la definición dada por nuestro código, podemos concluir que el elemento esencial es la confianza que inspira el mandatario al mandante.

Al respecto, Stitchkin expresa que "debemos sentar como premisa indiscutible que en el mandato interviene necesariamente este elemento interno o subjetivo: la confianza que induce al mandante a la celebración del contrato", ${ }^{23}$ en razón de lo anterior, manifestamos que este se trata de un contrato intuito personae, esto quiere decir que se ha celebrado en consideración a las partes, las que son determinantes en el contrato. ${ }^{24}$

El criterio de confianza impregnado en el contrato de mandato justifica los siguientes preceptos legales: en primer lugar, el artículo $2163 \mathrm{~N}^{\circ} 5 \mathrm{del}$ Código Civil que señala que "El mandato termina: 5. Por la muerte del mandante o mandatario.", y en segundo lugar, en concordancia con lo anterior, el artículo 2168 del mismo cuerpo legal que estipula "Sabida la muerte del mandante, cesará el mandatario en sus funciones".

En atención a estos artículos, queda de manifiesto que el contrato de mandato al estar fundado en el criterio de confianza, los derechos y obligaciones pactados no pueden pasar a los herederos del mandatario, tratándose, en consecuencia, de un contrato intransmisible.

Por lo tanto, el criterio de confianza, ya sea en el albaceazgo o en el contrato de mandato, resulta relevante para determinar si es o no transmisible la calidad de albacea a los herederos o los derechos y obligaciones que deriven del contrato.

A modo de conclusión, hemos establecido tres criterios que justifican que un derecho sea personalísimo, verificando en último término que se atiende a la idea de ser inherentes a la persona del titular, atendiendo a sus características y circunstancias, siendo, en consecuencia, el término personalísimo un concepto tautológico.

Habiendo establecido los tres criterios, nos queda referirnos a la situación

\footnotetext{
${ }^{23}$ Stitchkin Branover, David, El mandato civil, Editorial Jurídica, Santiago, 2003, p. 40.

${ }^{24}$ Ibídem, p. 163.
} 
particular de la acción indemnizatoria en atención a si puede esta calificarse como de aquellas personalísimas en virtud de estos criterios.

\section{Carácter no personalísimo de la acción por daño moral}

Como consecuencia del acaecimiento de un hecho que causa daño, surge para la víctima la posibilidad de reclamar el perjuicio causado, a través de un mecanismo procesal cual es la acción, en particular, la indemnizatoria.

Al respecto, en la literatura procesal se ha definido a la acción como "el poder jurídico que tiene todo sujeto de derecho, de acudir a los órganos jurisdiccionales para reclamarles la satisfacción de su pretensión". ${ }^{25}$

A partir de este punto, cabe hacer una distinción entre la acción que surge para reclamar el perjuicio y el daño en sí mismo. Sobre este punto Couture, haciendo la distinción entre acción y pretensión, explica que "la pretensión no es la acción. La acción es el poder jurídico de hacer valer la pretensión", ${ }^{26}$ es por lo anterior que la acción se ejerce para invocar un derecho que se tiene, la cual resulta diferente al daño causado.

En el caso de la acción que nace para reclamar la indemnización, esta surge como consecuencia de la afectación a la víctima ya sea en sus bienes o en su persona; en virtud de esto se ejerce la acción para reclamar una indemnización pecuniaria que compense el daño causado, el cual es independiente de la acción. Atendiendo a lo anterior, Corral expresa que "el daño debe haberse ya producido para que pueda accionarse de responsabilidad civil". ${ }^{27}$

Por su parte, el daño es coetáneo al surgimiento de la acción para reclamar su indemnización, por lo tanto, debe quedar clara la distinción entre ambos conceptos jurídicos. De acuerdo con Barros el daño responde a dos definiciones; la primera, como una lesión de un derecho subjetivo y, la segunda, como un "detrimento, perjuicio o menoscabo que se recibe por culpa de otro en la hacienda o la persona". ${ }^{28}$

En este sentido, podemos concluir que el daño se trata de aquellas situaciones personalísimas, en las que su producción va unida directa e inherentemente a la persona víctima de éste. Al respecto, la Corte Suprema en

\footnotetext{
${ }^{25}$ Couture Etcheverry, Eduardo, Fundamentos del derecho procesal civil, Euros Editores SRL, Buenos Aires, 2010, p. 47.

${ }^{26}$ Ibídem, p. 59.

${ }^{27}$ Corral Talciani, cit. (n. 1), p. 132.

${ }^{28}$ Barros Bourie, cit. (n. 1), p. 220; en este mismo sentido, Corral Talciani, cit. (n. 1), p. 132.
} 
un fallo manifiesta que "el daño es personal, cualquiera sea, sólo la víctima lo padece, con independencia si es patrimonial o extrapatrimonial. Por lo mismo el daño para ser indemnizado debe cumplir con el requisito que sea individual, que afecte a la víctima que demanda su reparación". ${ }^{29}$

En otro caso que fue conocido por el máximo tribunal de justicia, añade que hay que "coincidir con la jurisprudencia mayoritaria en orden a que el daño moral tiene el carácter personal, atendido a que se refiere al detrimento sufrido por la víctima y por lo tanto no puede sino pertenecer a ella". ${ }^{30}$

En base a lo anterior, podemos entender que el daño sufrido por una persona es personal o, incluso, personalísimo. Esta idea es reforzada por Barros, quien manifiesta que "la exigencia de que el daño sea personal significa que sólo quien lo ha sufrido puede demandar su reparación", ${ }^{31}$ pero además de esto, aclara que "no constituyen excepción a esta regla la transmisibilidad de la pretensión a los herederos de la víctima, ni el daño reflejo o por repercusión. Los herederos de la víctima actúan como causahabientes de la víctima fallecida, ejerciendo una acción de la que son sucesores... como la representan en todos sus derechos y obligaciones transmisibles, no ejercen derecho ajeno, sino uno que les es propio en virtud de la trasmisión hereditaria". ${ }^{32}$

No obstante lo anterior, referirse a que el daño sea personal no implica que la acción para reclamar su indemnización también lo sea. Es decir, resulta indiferente si el daño es personalísimo o inherente a la persona de quien lo sufre, puesto que de ello no se deriva que la acción tenga la misma calificación.

Además, hay que tener presente que el objeto de la transmisión no es el daño sufrido, sino que la acción para reclamarlo; en relación a esto, la Corte Suprema alude que "no es relevante que el daño sea individual o personalísimo si se quiere, pues el objeto de la transmisión no es el daño sino que la acción para reclamarlo. Aunque el daño sea personal, de eso no se deriva el carácter intransmisible de la acción indemnizatoria". ${ }^{33}$

En este sentido, para justificar la intransmisibilidad de la acción de indemnización, ésta debería ser calificada de personalísima, con lo que

\footnotetext{
${ }^{29}$ Corte Suprema, 27 de diciembre de 2016, cit. (n. 20).

${ }^{30}$ Corte Suprema, 26 de septiembre de 2016, Juan Caipillán Millalonco y otra con María Arismendi Carmimonei, Rol N 15206-2015.

${ }^{31}$ Barros Bourie, cit. (n. 1), pp. 240-241.

${ }^{32}$ Ibídem, p. 241.

${ }^{33}$ Corte Suprema, 27 de diciembre de 2016, cit. (n. 20).
} 
tendríamos que analizar los criterios que siguen a los derechos personalísimos para caracterizarlos como tales.

El artículo 951 del Código Civil expresa que "se sucede al difunto en todos sus bienes, derechos y obligaciones transmisibles", en relación con el artículo 1097 del mismo cuerpo legal, que estipula de acuerdo con los herederos que "representan la persona del testador para sucederle en todos sus derechos y obligaciones transmisibles", permite concluir que los herederos representan a la persona del causante en todos los derechos y obligaciones transmisibles.

De acuerdo a ello, debemos atender a algún aspecto que justifique que se haga una distinción de la acción indemnizatoria por daño moral de los otros derechos y obligaciones transmisibles a los herederos.

Con anterioridad, señalamos tres criterios en los que se fundamenta calificar a un derecho como personalísimo, correspondiendo a uno de tipo económico, de orden público y relativo a la confianza, con lo que pasaremos a analizar si la acción indemnizatoria obedece a esta categorización.

En cuanto al criterio económico, se señaló que los derechos son intransmisibles porque importan un desmembramiento de la propiedad y se prefiere la propiedad plena para transmitirla. ${ }^{34}$ En relación con este criterio, podemos señalar que la acción indemnizatoria, si bien tiene un carácter económico, puesto que su objeto es avaluar un perjuicio moral, el que se traduciría en una compensación monetaria, no responde al criterio económico relativo a los derechos reales limitados.

En atención a ello, la acción indemnizatoria no importa un desmembramiento de la propiedad, puesto que de acuerdo con el artículo 580 del Código Civil, el cual estipula que "los derechos y acciones se reputan bienes muebles o inmuebles, según lo que sea la cosa en que han de ejercerse, o que se debe" la acción tratándose de un bien, el cual tendría que calificarse como mueble puesto que su objeto es avaluar un daño en dinero, ingresa al patrimonio de los herederos, como continuadores de la persona del causante, de forma universal.

Sobre este punto, la Corte Suprema ha señalado: "La acción, en cuanto cosa, es un bien, al que corresponde calificar como mueble o inmueble, según dispone el artículo 581 del Código Civil. Dado que lo que se busca es la indemnización en dinero cabe reputar la acción indemnizatoria como un mueble". ${ }^{35}$

\footnotetext{
${ }^{34}$ En este sentido: Planiol y Ripert, cit. (n. 12), pp. 140-141; Mazeaud, Henri, León y Jean, cit. (n. 15), p. 260; Claro Solar, cit. (n. 13), p. 325.

${ }^{35}$ Corte Suprema, 27 de diciembre de 2016, cit. (n. 20).
} 
En consecuencia, la acción indemnizatoria por daño moral no puede ser calificada como intransmisible obedeciendo a este criterio económico relativo a los derechos reales limitados.

Por otra parte, en cuanto al criterio de orden público, en el cual encontrábamos el derecho de alimentos y las prestaciones sociales relativas a los accidentes laborales, concluimos que responden a aspectos relevantes socialmente y que el Estado debe ser quien garantice que dichos derechos se observen y, por lo tanto, dado la importancia que reporta su satisfacción, atienden a determinadas personas en cuanto a su calidad de tales; debemos analizar si la acción de indemnización por daño moral responde a este criterio.

Nuevamente estamos ante la interrogante relativa al objeto y la finalidad de la acción, la cual redunda entre la avaluación monetaria del daño moral y de ser una compensación o satisfacción patrimonial para la víctima de éste. A este respecto, debemos preguntarnos si puede equipararse el criterio de orden público al del objeto y finalidad de la acción indemnizatoria.

Mencionamos con anterioridad que este fundamento de orden público dice relación con la situación en la cual se encuentra una persona, ya sea para cubrir sus necesidades básicas de existencia o al sufrir un accidente laboral tendrá una serie de prestaciones que permiten atender al trabajador durante el período que dure su incapacidad o invalidez. En cuanto a la acción por daño moral, se trata de entregar una suma de dinero a quien sufrió el daño, es decir, una indemnización.

Entonces, de acuerdo con la acción, no se trata que el Estado tenga que procurar el resguardo de un derecho que es otorgado a una persona en relación a su situación, sino que es la víctima de un hecho ilícito o un incumplimiento contractual quien tiene que accionar para que se satisfaga su daño de una manera alternativa, esto es, que se le entregue una cantidad de dinero como compensación.

A este respecto, cabe concluir que la acción indemnizatoria no puede obedecer a un criterio de orden público, puesto que sus fundamentos y la forma de resguardar dichos derechos es distinta, así tenemos por una parte que el fundamento de orden público atiende a personas de acuerdo con una situación en particular y su protección por parte del Estado y, por otra parte, la acción indemnizatoria que busca cautelar un daño causado a los bienes extrapatrimoniales de la persona.

En forma adicional, tenemos que hacer la comparación de acuerdo con el criterio de confianza que mencionamos en el apartado anterior; en el supuesto del albaceazgo y del contrato de mandato, en los cuales la intransmisibilidad está basada en un criterio de confianza. 
En este sentido, la acción indemnizatoria no puede importar un criterio de confianza, toda vez que su surgimiento responde a la afectación de un derecho subjetivo, por lo que sería una forma de ejercer un resguardo de aquel derecho lesionado. En razón de ello, es que no podríamos fundar la intransmisibilidad de la acción aludiendo que entre el hechor o el incumplidor contractual y la víctima existe una confianza tal que sólo esta última puede accionar en contra del primero.

Como expresamos con anterioridad, el fundamento del albaceazgo y del contrato de mandato dice relación con la confianza en la persona a la cual se constituye como albacea o como mandatario. ${ }^{36}$ En la acción indemnizatoria no podemos encontrar un fundamento tal, puesto que se trata de cautelar un interés lesionado. Desde ya se descarta este fundamento, puesto que es incongruente seguir el razonamiento de su intransmisibilidad en base a la confianza, en consecuencia, la acción no puede calificarse como personalísima y negar su transmisión de acuerdo con este criterio.

En consecuencia, la acción de indemnización por daño moral no responde a los criterios o fundamentos de los derechos intransmisibles que hemos planteado con anterioridad, por lo tanto, de acuerdo a ellos no podría ser calificada como intransmisible.

En este orden de ideas, la regla general es la transmisibilidad de los derechos y obligaciones, y la excepción sería la intransmisibilidad. Esta última al ser una excepción tiene que estar expresamente señalada u obedecer a los criterios que funden los derechos personalísimos, lo que en estos supuestos no ha acaecido.

La Corte Suprema aludiendo a la falta de estipulación acerca de la transmisibilidad o intransmisibilidad de la acción ha expresado que "el legislador no lo ha dicho en forma expresa, lo que puede entenderse, dado el surgimiento tardio de la indemnización del daño moral". ${ }^{37}$ Se trata de un razonamiento bastante elocuente que permite justificar que no se haya establecido una excepción de forma expresa.

Sin embargo, esto no puede ser un impedimento para calificar a la acción de intransmisible, puesto que tampoco responde los criterios que hemos establecido de acuerdo a los derechos personalísimos. Así lo agrega en el mismo

\footnotetext{
${ }^{36}$ En relación al albaceazgo: Domínguez Benavente, Ramón; Domínguez Águila, Ramón, Derecho Sucesorio, Editorial Jurídica, Santiago, 2011, T. III, p. 1191.; Meza Barros, cit. (n. 21), p. 151; Elorriaga De Bonis, cit. (n. 22), p. 675.; en relación al mandato: Oliva Murillo, Raúl, Naturaleza jurídica del mandato civil, Ed. Luxe, Santiago, 1939, p. 63; Stitchkin Branover, cit. (n. 23), p. 40.

${ }^{37}$ Corte Suprema, 27 de diciembre de 2016, cit. (n. 20).
} 
fallo la Corte Suprema, expresando que "tampoco se justifica asignarle el carácter de intransmisible por razones económicas o de confianza. Asignarle el carácter intransmisible a la acción, lo que constituye una excepción a la regla general, requiere un fundamento, que hasta el momento no se ha otorgado". ${ }^{38}$

En síntesis, podemos manifestar que no es posible calificar la acción de indemnización por daño moral como personalísima, y en consecuencia intransmisible, dado los argumentos que se han presentado en este capítulo.

\section{PATRIMONIALIZACIÓN OPATRIMONIALIDAD DE LA INDEMNIZACIÓN}

Tanto a nivel doctrinal como jurisprudencial existe consenso en cuanto a señalar que la indemnización en los supuestos de daño moral tiene una naturaleza compensatoria o satisfactiva, puesto que en este tipo de perjuicios no puede ser reparatoria. No obstante lo anterior, cabe señalar que la acción para reclamar dicha indemnización tiene un eminente contenido patrimonial.

En razón de ello, es que aquí se pretende evidenciar la patrimonialidad de la acción indemnizatoria, diferenciándola de la extrapatrimonialidad del daño en sí. Además, establecer que con independencia de si la muerte del sujeto ocurre de forma instantánea o se prolonga en el tiempo, la acción se transmite puesto que se trata de un bien mueble que ingresa al patrimonio.

En atención a lo que hemos señalado con anterioridad en relación a que el daño es personalísimo, siendo este inherente a la persona que lo sufre $y$, en consecuencia, intransferible e intransmisible, distinta es la situación de la acción que nace para reclamar su indemnización.

Estableciendo que nuevamente se debe hacer la distinción entre daño sufrido y acción que surge producto del daño, cabe señalar que bajo este supuesto dicha acción tiene un contenido eminentemente patrimonial, a diferencia del daño el que es esencialmente extrapatrimonial. A este respecto Domínguez señala que "cuando se trata de daño no patrimonial o moral, se sabe que la indemnización no puede cumplir el mismo propósito, desde que por esencia, tales daños constituyen la afectación de un bien o interés que no tiene traducción dineraria", ${ }^{39}$ por su parte, Barros explica que "los daños morales, por el contrario, son inconmensurables en dinero, porque no existe mercado para la vida, la salud o el honor, ni es legítimo poner a una persona en la situación de poner precio a esos bienes". ${ }^{40}$

\footnotetext{
38 Ídem.

${ }^{39}$ Domínguez Águila, cit. (n. 1), p. 509.

${ }^{40}$ Barros Bourie, cit. (n. 1), p. 233.
} 
A esto se agrega la función de la indemnización en un daño que es extrapatrimonial o no patrimonial, la cual como ha sido explicado, es compensatoria o satisfactiva, en que no se pretende igualar el perjuicio a una cantidad de dinero, sino perseguir un aplacamiento del dolor a través de esta compensación.

El argumento que se ha utilizado para negar la transmisibilidad de la acción por daño moral dice relación con que aquélla tiene un carácter extrapatrimonial, la cual responde al daño que se le ha ocasionado a la víctima y sólo a ésta. En razón de lo anterior, Viney y Markesinis manifiestan que "se trata, en efecto, de perjuicios que, por definición, son intraducibles en términos monetarios". ${ }^{41}$ Por su parte, Domínguez Á. alude que: "Ese principio no puede regir para los daños morales y, por lo mismo, como no hay posibilidad de reposición la idea no puede ser la de dar a la indemnización un carácter reparatorio", ${ }^{42}$ agrega además que "es, para el heredero, sólo una fuente de ganancia, sin función compensadora, es decir, una ventaja sin causa. La reparación entregada a quien no ha sufrido el daño no cumpliría función alguna". ${ }^{43}$

En materia de responsabilidad civil se hace la distinción entre daños patrimoniales y daños no patrimoniales. Los primeros pueden definirse como "aquellos que afectan bienes que tienen un significado económico, que se expresa en un valor de cambio. Es daño patrimonial el que se traduce en una disminución del activo (en razón de la destrucción o deterioro de una cosa, de gastos en que la víctima debe incurrir, o por cualquiera otra pérdida patrimonial), o porque el hecho del responsable ha impedido que el activo se incremente", ${ }^{44}$ dentro de estos encontramos el daño emergente y el lucro cesante, a su vez Corral señala que "el daño es patrimonial cuando consiste en una pérdida pecuniaria, en un detrimento del patrimonio". ${ }^{45}$

El daño no patrimonial, por su parte, tiene una definición imprecisa, la que tiende a identificarse con el daño moral, razón por la cual se suele definir en términos negativos como aquel daño que no es patrimonial.

Lo esencial en la distinción en estos tipos de daños es el contenido económico, así por ejemplo, en el caso de los daños patrimoniales se pueden avaluar de acuerdo con criterios más o menos exactos, los que permiten

\footnotetext{
${ }^{41}$ VinEY, Geneviève; MARKESINIs, Basin, La reparation du dommage corporel. Essai de comparaison des droits anglais et francais, Ed. Economica, Paris, 1985, p. 140.

${ }^{42}$ Domínguez Águila, cit. (n. 1). p. 510.

${ }^{43}$ Ibídem, p. 513.

${ }^{44}$ Barros Bourie, cit. (n. 1), p. 231.

${ }^{45}$ Corral Talciani, cit. (n. 1), p. 142.
} 
establecer una cierta equivalencia entre el daño y su reparación, ${ }^{46}$ a diferencia de los daños extrapatrimoniales que desde su naturaleza no pueden traducirse en un perjuicio económico.

Hecha esta distinción entre los daños patrimoniales y no patrimoniales, corresponde distinguir entre el daño y la acción que nace para su reclamación. A este respecto, postulamos que el contenido de la acción responde a uno de tipo económico, es decir, que lo que se busca al impetrar una acción indemnizatoria, en la mayoría de los casos, es que se avalúe monetariamente un perjuicio moral, lo que denota inevitablemente un carácter pecuniario o patrimonial de la indemnización, con independencia de la función que cumpla en la responsabilidad civil.

Esta argumentación la ha recogido la Corte Suprema, señalando al respecto que: "Desde el momento que aceptamos que verificado el daño moral nace una acción para reclamar la indemnización, existe un carácter patrimonial que se introduce. Mientras el daño lo calificamos como extrapatrimonial para diferenciarlo del daño emergente y lucro cesante que repercuten en forma inmediata en el patrimonio, acá, tratándose del daño moral, éste se refleja en una pretensión a través de la acción que busca la indemnización, pero también con una impronta patrimonial". ${ }^{47}$

En virtud de lo anterior, es que al introducirse un carácter patrimonial en la indemnización por daño moral, el argumento sobre la intransmisibilidad de la acción indemnizatoria de daño moral en atención a que ésta tiene por finalidad compensar o dar una satisfacción alternativa, ya no puede ser procedente, toda vez que el objeto que se reclama es una avaluación pecuniaria del daño, lo que importa una patrimonialización de la acción.

En razón de lo expuesto, coincidimos con el argumento que esgrime la Corte Suprema en el considerando quinto del mismo fallo, cuando expresa que: "No podría justificarse el rechazo a la transmisibilidad en la función del daño moral, pues como cualquier acción indemnizatoria lo que se busca con su ejercicio es el pago de una cantidad de dinero que refleje el daño ocasionado". ${ }^{48}$

De acuerdo a lo señalado con anterioridad, el contenido patrimonial de la acción indemnizatoria por daño moral no puede ser obviado. Se manifiesta un carácter intrínsecamente pecuniario, cuyo objeto es avaluar un daño que no tiene un equivalente en dinero.

\footnotetext{
${ }^{46}$ Barros Bourie, cit. (n. 1), p. 233.

${ }^{47}$ Corte Suprema, 27 de diciembre de 2016, cit. (n. 20).

48 Ídem.
} 
Podemos señalar, a modo de ejemplo, que existen acciones mediante las cuales se reclama el daño moral cuyo objeto no es la avaluación pecuniaria del perjuicio sino que otra forma de compensación, la que responde de una forma más exacta a un criterio de extrapatrimonialidad en la reparación. Encontramos aquí el caso de daño a los derechos de la personalidad, en particular el derecho a la privacidad y a la honra.

En estos supuestos frente a la afectación de tales derechos nacen dos tipos de acciones que tienen por finalidad la cesación o la reparación del perjuicio cometido, así entonces encontramos las acciones que intentan proteger ex ante y ex post a la víctima del ilícito. Las primeras tienen por objeto la prevención o cesación del daño, mientras que las segundas, una vez producido el perjuicio, reparar en naturaleza o por equivalencia al afectado. ${ }^{49}$

Lo que nos interesa destacar dice relación con la protección de los derechos de la personalidad en el orden ex post, es decir, una vez acaecido el daño. A este respecto, las acciones que deben primar son las que permiten reparar el perjuicio en naturaleza, o sea, formas de reparación no patrimonial tales como el derecho a réplica, rectificación, retractación o la publicación de la sentencia. ${ }^{50}$ Como podemos observar respecto de estas acciones, su finalidad es reparar a la víctima el mal causado, y el contenido de las mismas se traduce en uno extrapatrimonial, puesto que la forma de reparación no se traduce en la entrega de una suma de dinero que compense el perjuicio sino que la idea es una reparación en naturaleza, dejando al afectado en una posición tal como si el perjuicio o el daño no hubiese ocurrido.

Podemos convenir en que estas acciones tienen un carácter extrapatrimonial porque lo que hacen es reparar a aquella víctima de un perjuicio de una forma totalmente distinta a lo que haría una acción que tenga un contenido patrimonial o pecuniario.

Entonces si tenemos acciones cuyo objeto no es ser un correlato entre el daño y un equivalente monetario, estas tienen que calificarse como acciones extrapatrimoniales. A diferencia de lo que ocurre usualmente en la indemnización por daño moral en que en la mayoría de los casos se suele reclamar una cantidad de dinero para satisfacer un perjuicio causado. Esta acción indudablemente tiene un carácter patrimonial.

En consecuencia, no puede ser procedente el argumento de la extrapatrimonialidad de la indemnización, lo que impide que se transmita la

\footnotetext{
${ }^{49}$ Barros Bourie, cit. (n. 1), pp. 591-609.

${ }^{50}$ Ibídem, pp. 597-599.
} 
acción por daño moral, toda vez que se ha evidenciado la impronta económica que se persigue al impetrar dicha acción.

En este entendido, manifestamos que la finalidad de la indemnización por daño moral si bien es compensatoria o como una satisfacción alternativa, ello no impide la transmisibilidad, puesto que al traducirse monetariamente la indemnización importa una patrimonialidad de la pretensión, siendo independiente lo personal o incluso personalísimo del daño.

Habiendo establecido el carácter patrimonial de la acción, descartando a su vez el argumento de la intransmisibilidad de la acción indemnizatoria por daño moral en virtud del carácter no patrimonial de la acción, nos queda por señalar que resulta indiferente el momento de la muerte del sujeto, puesto que la acción, independiente del lapso transcurrido entre el ilícito y la muerte del sujeto, ingresa al patrimonio del causante.

El artículo 565 del Código Civil estipula que los bienes se dividen en cosas corporales o incorporales, se alude que las cosas corporales son "las que tienen un ser real y pueden ser percibidas por los sentidos, como una casa, un libro", en cambio las cosas incorporales son "las que consisten en meros derechos, como los créditos, y las servidumbres activas", en relación a lo anterior, la acción debe calificarse como un bien incorporal. A su vez, el artículo 576 señala que: "Las cosas incorporales son derechos reales o personales".

En este sentido, la acción indemnizatoria consistiría en una cosa incorporal personal, puesto que de acuerdo con Alessandri aludiendo a los derechos personales manifiesta que "es el que nace de la relación de dos personas, en virtud de la cual una de ellas (deudor) se encuentra en la necesidad de cumplir una prestación (dar, hacer o no hacer algo), y la otra (acreedor) tiene la facultad de exigir tal prestación". ${ }^{51}$ Agrega a modo de ejemplo que "la prestación debida puede consistir, por ejemplo, en la transferencia de una casa; en el pago de una suma de dinero...". 52

Por su parte, el artículo 580 del Código Civil en su inciso primero define a la acción como un bien mueble o inmueble según sobre qué se ejerza, expresa que: "Los derechos y acciones se reputan bienes muebles o inmuebles, según lo sea la cosa en que han de ejercerse, o que se debe". En virtud de lo anterior, cabe señalar que la acción indemnizatoria para reclamar el daño moral se ejerce sobre el dinero, puesto que es esto lo que debería el hechor a la víctima, en consecuencia se trataría de un bien mueble.

${ }^{51}$ Alessandri Rodríguez, Somarriva Undurraga y Vodanovic Haklicka, cit. (n. 14), p. 15.

52 Ídem. 
Atendiendo a lo señalado, cabe concluir que la acción indemnizatoria es de aquellas cosas corporales, consistiendo en una acción personal y que a su vez es un bien mueble. Establecido esto, nos queda explicar cómo es que este bien ingresa al patrimonio de un sujeto.

De acuerdo con Figueroa, la visión de patrimonio que está contenida en nuestro Código Civil es del tipo pragmática o realista, señala que aquélla se asimila en algunas ocasiones a la concepción clásica o subjetiva del patrimonio, seguida por la doctrina Francesa, la que postula que se trata de un atributo de la personalidad, y otras veces se asemeja a la visión objetiva o de afectación, postulada por la doctrina Alemana, en donde lo relevante es la afectación de la universalidad jurídica a una finalidad determinada. ${ }^{53}$

Por su parte, Fueyo, refiriéndose al concepto de patrimonio en nuestro ordenamiento jurídico, alude que en la mayoría de los casos en que en los artículos del Código Civil se utiliza la voz patrimonio, se refieren a "los bienes, derechos y acciones que constituyen el contenido de la universalidad y, en algunas ocasiones, asimismo a las deudas y obligaciones que también integran ese contenido", ${ }^{54}$ lo que hace deducir la equivalencia terminológica entre el concepto de patrimonio y los bienes. ${ }^{55}$

En virtud de lo anterior, cabe reiterar sobre este punto que la acción constituye un bien que tiene el carácter de mueble, cuestión que ha sido establecida por el Código Civil chileno. En consecuencia, este bien forma parte integrante del patrimonio de un sujeto para todos los efectos jurídicos.

En materia de sucesión, resulta relevante el inciso segundo del artículo 951 del Código Civil, cuando estipula que "se sucede al difunto en todos sus bienes, derechos y obligaciones transmisibles, o en una cuota de ellos", puesto que perfila un concepto de patrimonio al establecer que se trata de bienes, derechos y obligaciones, ${ }^{56}$ los que serán transmitidos a los herederos del causante. Sobre esta misma línea, el artículo 1097 del mismo cuerpo legal toma importancia en cuanto refuerza la idea anterior, aludiendo a que los herederos "representan la persona del testador para sucederle en todos sus derechos y obligaciones transmisibles", en consecuencia, la idea de patrimonio engloba los bienes, derechos y obligaciones que tenía el sujeto al momento de

\footnotetext{
${ }^{53}$ Figueroa YÁñez, Gonzalo, El Patrimonio, Editorial Jurídica, Santiago, 1997, pp. 27-102.

${ }^{54}$ Fueyo Laneri, Fernando, Repertorio de voces y giros del Código Civil chileno, Ed. Revista de derecho privado, Santiago, 1952, T. III, pp. 38-39.

${ }^{55}$ Figueroa Yáñez, cit. (n. 53), p. 86.

${ }^{56}$ FigueroA YáñEz, cit. (n. 53), p. 88.
} 
su muerte, los que son transmitidos a sus herederos por el sólo ministerio de la ley por medio de la ficción legal de aquéllos como continuadores de la persona del causante.

Lo determinante en el aspecto de la sucesión es que los herederos no reciben bienes determinados, sino una universalidad jurídica que es el patrimonio del causante o una cuota del mismo. ${ }^{57} \mathrm{La}$ única excepción que encontramos en esta materia es lo estipulado por los artículos 951 y 1097 del Código Civil en cuanto limitan la sucesión solamente al patrimonio transmisible.

Como se ha señalado con anterioridad, los derechos intransmisibles son aquellos que el legislador ha establecido expresamente por tener un contenido de orden público, como el derecho de alimentos o las prestaciones laborales en materias de accidentes del trabajo; también aquellos con un carácter eminentemente económico que importan un desmembramiento de la propiedad o, por último, aquellos establecidos en función de la confianza que reportan entre las partes.

En virtud de lo anterior, la acción para reclamar la indemnización al no coincidir con estos criterios que hemos expuesto, no puede catalogarse como de aquellas intransmisibles.

Refuerza este punto la circunstancia que el mismo legislador ha expresado que la acción constituye un bien; calificado de este modo, no cabe sino concluir que forma parte integrante del patrimonio de una persona $y$, por lo tanto, se transmite a sus herederos. En este sentido, se alude a que el patrimonio tiene ciertas características pero a pesar de ellas, para la doctrina francesa resulta transmisible a los sucesores, a este respecto se señala que "a pesar de ser incomerciable, inalienable e inembargable, el patrimonio, para los clásicos, es transmisible"; 58 en virtud de lo anterior, las acciones que pueden surgir frente a la producción de un ilícito civil se tienen por incorporadas al patrimonio de la víctima, por lo tanto, si aquélla fallece, consecuentemente transmite su patrimonio a sus herederos, los que continúan como la persona del causante.

En relación a lo expresado, es que resulta indiferente, entonces, si la persona falleció al instante o medió algún tiempo entre la producción del ilícito y la muerte, puesto que producido el daño, surge la acción la que ingresa al patrimonio del causante y, en consecuencia, se transmitiría a los herederos.

En forma adicional a que la acción forma parte del patrimonio del

\footnotetext{
${ }^{57}$ Figueroa YÁÑez, cit. (n. 53), p. 472.

${ }^{58}$ Ibídem, p. 136.
} 
causante al momento de su muerte, hemos establecido que el contenido de la acción indemnizatoria es uno de carácter monetario o pecuniario, sin perjuicio que el daño que intenta reparar, esto en un sentido amplio, es no patrimonial o extrapatrimonial. Este contenido evidentemente económico que se traduce en la indemnización por daño moral, por ser tal, ingresa al patrimonio del causante de forma similar que la indemnización por daño emergente o lucro cesante, aspectos que al igual que la acción indemnizatoria por daño moral, manifiestan un aspecto pecuniario, por ende, no cabe hacer distinción de si una u otra acción ingresa o no al patrimonio de la víctima, teniendo que concluir necesariamente que forma parte de los bienes, derechos y obligaciones transmisibles.

\section{CONCLUSIONES}

En relación a lo expuesto a lo largo del presente estudio, se hace necesario señalar las siguientes conclusiones:

1. La doctrina y la jurisprudencia tradicional limitaban el concepto de daño moral al Pretium doloris, razón por la cual negaron la posibilidad de la transmisión de la acción por daño moral a los herederos del causante, justificando que es la víctima la única que puede sufrir por el daño que le ha sido causado mediante un ilícito.

2. Con el transcurso del tiempo se ha acogido una noción amplia del daño moral que se vincula con la afectación a derechos subjetivos. Nuestro postulado es que el daño moral ocasionado cuando la víctima del ilícito fallece es la fractura al proyecto de vida y es aquello lo que se indemniza.

3. La función que cumple la indemnización en la responsabilidad civil es eminentemente reparatoria, pero en el caso en que la víctima sufra daño moral ya no puede significar la reparación del perjuicio, sino una compensación o una satisfacción alternativa para el afectado que pueda aplacar de otras formas el daño acaecido, cuestión que en general se trata de una indemnización traducida en dinero.

4. La doctrina tradicionalmente ha negado la transmisibilidad de la acción por daño moral señalando que se trata de una acción o un daño personalísimo, tendiendo a confundir daño y acción. Cabe destacar que respecto al daño no se puede negar que sea personal o incluso personalísimo para quien lo sufre, pero una cuestión distinta es la acción que surge para reclamarlo, la cual no puede ser catalogada como personalísima.

5. Analizados los derechos personalísimos, llegamos a la conclusión que lo personalísimo en sí es tautológico, en el sentido en que para definirlo se acude a que algo personalísimo es inherente a la persona, que atiende a sus 
circunstancias y características en particular.

6. Hemos establecido tres criterios para definir a un derecho como personalísimo, encontrando uno de tipo económico, en el cual se establece que como reportan un desmembramiento de la propiedad, sólo el titular puede ejercerlo; también un criterio de tipo social o de orden público, en el sentido que el legislador ha establecido ciertos derechos que tienen una impronta particular para determinadas personas, como lo son los alimentos y las prestaciones laborales en materia de accidentes del trabajo; y por último un criterio de confianza, en el cual se celebran ciertos actos atendiendo a la confianza entre las partes, cuestión que no puede extenderse a otras personas, como el caso del mandato o el albaceazgo.

7. Analizados los criterios que agrupan los derechos que son considerados como personalísimos y, en consecuencia, intransmisibles, podemos evidenciar que la acción para reclamar la indemnización por daño moral no se asemeja a dichos criterios, sino que su finalidad es reclamar una compensación o satisfacción alternativa para la víctima del daño.

8. Teniendo clara la distinción entre daño y acción, cabe concluir que el daño moral se caracteriza por ser extrapatrimonial, es decir, no puede establecerse un equivalente en dinero al perjuicio sufrido, en cambio, es innegable el contenido patrimonial de la acción indemnizatoria puesto que lo que se hace es entregar una suma de dinero a la persona, quien fue víctima del ilícito.

9. La acción es definida en el Código Civil como un bien de carácter mueble, al ser tal forma parte del patrimonio del causante, puesto que como hemos señalado el concepto que contempla nuestro código se sintetiza en que son bienes, derechos y obligaciones que una persona tiene, lo que ratifican los artículos 951 y 1097 de dicho cuerpo legal.

10. Correspondiendo la acción a un bien que el causante tiene en su patrimonio, resulta indiferente la distinción acerca del momento de producción de la muerte. En virtud de lo anterior, la acción ingresa al patrimonio de la víctima y se transmite a sus herederos.

11. En síntesis, la acción para reclamar el daño moral no encuentra impedimentos para ser transmitida a los herederos, en consecuencia, la tesis de la intransmisibilidad debe rechazarse.

\section{BIBLIOGRAFÍA}

Alessandri Rodríguez, Arturo, Derecho Civil: título preliminar. De las personas. Editorial Lex, Santiago, 1933. 
Alessandri Rodríguez, Arturo, De la responsabilidad extracontractual en el derecho civil chileno. Editorial Jurídica, Santiago, 2005 (reimpresión).

Alessandri Rodríguez, Arturo, Somarriva Undurraga, Manuel; Vodanovic Haklicka, Antonio, Tratado de los derechos reales. Ediciones Jurídicas de Santiago, Santiago, 2016.

Barcia Lehmann, Rodrigo Fundamentos del derecho de familia y de la infancia. Santiago: Thomson Reuters, Santiago, 2011.

BARRIEntos Zamorano, Marcelo, "Del daño moral al daño extrapatrimonial: la superación del pretium doloris", Revista Chilena de Derecho, 2008, vol. 35 $\mathrm{N}^{\circ} 1$.

Barros Bourie, Enrique, Tratado de responsabilidad extracontractual. Editorial Jurídica, Santiago, 2006.

Bidart Hernández, José, Sujetos de la acción de responsabilidad extracontractual. Editorial Jurídica, Santiago, 2005.

Burgos, Osvaldo, Daños al proyecto de vida. Astrea, Buenos Aires, 2012, $440 \mathrm{p}$.

Claro Solar, Luis, Explicaciones de derecho civil chileno y comparado, Santiago: Editorial Jurídica, 1992, Vol, III.

CORRAL TALCIANI, Hernán, Lecciones sobre la responsabilidad extracontractual. Thomson Reuters, Santiago, 2013.

COUture EtcheVerry, Eduardo, Fundamentos del derecho procesal civil. Euros Editores SRL. Buenos Aires, 2010.

Diez Schwerter, José L., "La culpa del empresario por accidentes del trabajo: Modernas tendencias jurisprudenciales", en Baraona González, J.; Zelaya Etchegaray, P. (Coords.), La responsabilidad por accidentes del trabajo. Cuadernos de Extensión Jurídica N ${ }^{\mathrm{o}}$ 10, Universidad de los Andes, Santiago, 2005.

Domínguez Águila, Ramón, "Sobre la transmisibilidad de la acción por daño moral", Revista Chilena de Derecho, 2004, vol. 31 № 3.

Domínguez Benavente, Ramón; Domínguez Águila, Ramón, Derecho Sucesorio, Editorial Jurídica, Santiago, 2011, T. III.

Domínguez Hidalgo, Carmen, El daño moral. Editorial Jurídica, Santiago, 2000.

Elorriaga de Bonis, Fabián, Derecho Sucesorio, Legal Publishing, Santiago, 2010.

Fernández Sessarego, Carlos, "El daño al proyecto de vida", Revista de derecho de la Pontificia Universidad Católica del Perú, 1996, № 50.

Figueroa YáÑez, Gonzalo, El Patrimonio, Editorial Jurídica, Santiago, 1997. 
Fueyo Laneri, Fernando, Repertorio de voces y giros del Código Civil chileno, Ed. revista de derecho privado, Santiago, 1952, T. III.

Fueyo LANERI, Fernando, Derecho civil: derecho de familia, Ed. Universo, Valparaíso, 1959.

Mazeaud, Henri; Mazeaud, León; Mazeaud, Jean, Lecciones de Derecho Civil, Luis Alcalá-Zamora y Castillo (trad.), Ediciones jurídicas EuropaAmérica, Buenos Aires, 1959.

Meza Barros, Ramón, Manual de la sucesión por causa de muerte y donaciones entre vivos, Editorial Jurídica, Santiago, 2000 (reimpresión).

Oliva Murillo, Raúl, Naturaleza jurídica del mandato civil, Ed. Luxe, Santiago, 1939.

Peñallillo Arévalo, Daniel, Los bienes. Editorial Jurídica, Santiago, 2006.

Planiol, Marcel; Ripert, Georges, Tratado elemental de Derecho Civil. José M. Cajica (trad.), Cardenas Editor y Distribuidor, México D.F., 1983.

Rodríguez Grez, Pablo, Responsabilidad extracontractual, Santiago, Editorial Jurídica, 2002.

Stitchkin Branover, David, El mandato civil, Santiago, Editorial Jurídica, 2003.

Viney, Geneviéve; Markesinis, Basin, La reparation du dommage corporel. Essai de comparaison des droits anglais et francais, Ed. Economica, Paris, 1985.

\section{JURISPRUDENCIA CITADA}

Corte de Apelaciones de Concepción, 26 de abril de 2003, Tania Andrea Mendoza Alarcón, Sebastián Marihuén Marihuén, Manuel Aniñir Epullán, Bernarda Marisol Aniñir Marileo y Roberto Gabriel Concha Mathiesen con Jaime Corona Aravena, Rol No 4825-2003.

Corte Suprema, 27 de junio de 2007, Lucía Porman Barahona, Lucía Ramos Porman y Antonio Ramos Porman con Empresa Pesquera Bío Bío, Rol $\mathrm{N}^{\circ} 309-2006$.

Corte Suprema, 27 de noviembre de 2007, María Inés Amestoy Klenner y otros con Transportes Calafquén Limitada, Rol № 6196-2006.

Corte de Apelaciones de Concepción, 12 de diciembre de 2007, Elizabeth del Carmen Huentemil Fuentes y otros con Agro Inversiones S.A., Rol N 423-2007.

Corte de Apelaciones de Valdivia, 20 de abril de 2010, Sucesión de Cortez 
Villagrán, Germán Enríquez contra Cooperativa de Servicios Educacionales Windsor School Ltda., Rol N 52-2010.

Corte Suprema, 29 de septiembre de 2011, Ricardo Armando Mellao Calfuan y María Francisca Llancao Colin con Fisco de Chile, Rol No 2073-2009.

Corte de Apelaciones de Santiago, 8 de noviembre de 2011, Susana Lillo Cuevas con Distribuidora de Industrias Nacionales S.A., Rol No 1910-2011.

Corte Suprema, 23 de noviembre de 2011, María Inés Retamales Soto y otros con Servicio de Salud Metropolitano Norte, Rol N 6669-2009.

Corte Suprema, 11 de agosto de 2015, Consejo de Defensa del Estado y otros con Hernán Ramírez Rurange, Rol N 8278-2013.

Corte de Apelaciones de San Miguel, 4 de mayo de 2016, María Quezada Gallardo con Colmenares Werner Limitada, Rol No 84-2016;

Corte Suprema, 27 de diciembre de 2016, María Quezada Gallardo con Colmenares Werner Limitada, Rol N 33.990-2016. 